\title{
Bell's Palsy and COVID-19: A Connection with Concern
}

\author{
Gargi S Sarode ${ }^{1}$, Namrata Sengupta ${ }^{2}$, Urmi Ghone ${ }^{3}$, Sachin C Sarode ${ }^{4 \oplus}$, Shankargouda Patil ${ }^{5}$
}

Keywords: Bell's Palsy, COVID-19, Neural Pathology, SARS-CoV-2.

World Journal of Dentistry (2022): 10.5005/jp-journals-10015-1892

\section{INTRODUCTION}

Coronavirus disease-2019 (COVID-19) pandemic has challenged the world with a myriad of health consequences. Though respiratory complications have been most commonly encountered, other disorders have also been reported in COVID-19 patients. Studies have seen that respiratory tract is not the only confinement zone for the virus but it can even invade the central nervous system. ${ }^{1}$ The potential neuroinvasion property of human coronavirus in vulnerable individuals has been documented in many studies leading to several neurological pathologies such as encephalitis, encephalopathy, rhabdomyolysis, and Guillain-Barre syndrome in individuals with COVID-19., ${ }^{1,2}$

\section{Bell's Palsy and COVID-19}

Facial nerve disease causing peripheral facial palsy is another neurological manifestation being reported in some patients diagnosed with COVID-19. ${ }^{3,4}$ Idiopathic facial paralysis or Bell's Palsy (BP) is a condition where there is an onset of unilateral peripheral paralysis of the facial nerve (seventh cranial nerve). Though still unclear, some of the identifiable etiological factors of BP are viral infections, ischemia, inflammation, and cold exposure. ${ }^{5}$ Infection by reactivated viruses is one of the most potential risk factors of BP. Varicella zoster virus (VZV) and herpes simplex virus (HSV) are potent in causing infections and maintaining a latent phase in different ganglia of the neuroaxis. In immunocompromised hosts these viruses are more likely to reactivate in the geniculate ganglion, replicate and spread through the branches of facial nerve causing facial paralysis. Ischemic nerve damage, inflammatory reactions, and even psychological factors are the other major causes of BP. Inflammatory and autoimmune mediated reactions can cause facial nerve demyelination. ${ }^{5}$

The neuroinvasion property of SARS-CoV-2 virus could be considered as a possible viral etiology for idiopathic facial nerve paralysis. The virus gains easy access to the brain through the olfactory pathway and causes inflammatory and demyelinating reactions. ${ }^{1}$ Moreover, the main target receptor, ACE2 receptor, of the virus is widely expressed in the epithelial cells of respiratory tract, brain, endothelial cells, glial cells, motor cortex and basal ganglion. SARS-CoV-2 can travel through hematogenous route and infect the endothelial cells of blood-brain barrier. The virus then gets accumulated in the ACE2 rich brain regions and affects the individual with neurological pathologies. ${ }^{1}$ The extended and convoluted pathway of the facial nerve makes it more susceptible to palsy than other nerves. ${ }^{5}$ Studies also suggest that micro-thrombi and vascular changes reported in COVID-19 patients might pave the path for development of facial nerve ischemia. ${ }^{3}$

Apart from vascular changes the SARS-CoV-2 virus causes a severe immunocompromised state in the affected individual.
${ }^{1-4}$ Department of Oral Pathology and Microbiology, Dr DY Patil Dental College and Hospital, Dr DY Patil Vidyapeeth, Pimpri, Pune, Maharashtra, India

${ }^{5}$ Department of Maxillofacial Surgery and Diagnostic Sciences, Division of Oral Pathology, College of Dentistry, Jazan University, Jazan, Saudi Arabia

Corresponding Author: Sachin C Sarode, Department of Oral Pathology and Microbiology, Dr DY Patil Dental College and Hospital, Dr DY Patil Vidyapeeth, Pimpri, Pune, Maharashtra, India, Phone: +91 9922491465, e-mail: drsachinsarode@gmail.com

How to cite this article: Sarode GS, Sengupta N, Ghone U, et al. Bell's Palsy and COVID-19: A Connection with Concern. World J Dent 2022;13(1):1-2.

Source of support: Nil

Conflict of interest: None

Immunodeficiency is an ideal condition for reactivation of latent $\mathrm{HSV}$ in the peripheral nervous system. ${ }^{6}$ Reactivation of latent viral infections is one of the most important causative factors of BP. It is also a common trigger for cytokine storm in immunosuppressed individuals. ${ }^{1}$ Studies have reported that infecting cultured glial cells with SARS-CoV-2 viral particles have caused huge production of inflammatory mediators. ${ }^{7}$ This exaggerated inflammatory or immune reaction might contribute in developing demyelinating neural damage.

\section{Bell's Palsy and COVID-19 Vaccine}

Not only COVID-19, but vaccines against the virus have also been reported to cause BP. ${ }^{8}$ Peripheral facial nerve palsy has been suggested to be a possible detrimental effect following BNT162b2 (Pfizer-BioNTech) vaccine. ${ }^{9}$ Trial reports published regarding the efficiency of the vaccine mentioned $4(0.009 \%)$ cases of BP in the vaccinated group and none in the control group. ${ }^{10,11} \mathrm{~A}$ study by Wan et al. reported the development of BP in 16 cases post BNT162b2 vaccine and 28 confirmed cases following vaccination with CoronaVac which uses inactivated viral particles. ${ }^{12}$ Similar adverse effects have been reported with mRNA COVID-19 vaccine (Moderna). Three confirmed cases of BP were observed in the vaccinated group. ${ }^{10}$ Previous papers have also reported the same in children post vaccination, wherein, diphtheria, influenza [154 (78.2\%)] and meningococcal vaccines were the etiologies. ${ }^{13,14}$ The use of adjuvants were thought to start an immunomodulatory reaction leading to adverse neurological effects. However, the vaccines of Pfizer-BioNTech and Moderna did not involve the use of adjuvants. ${ }^{9}$ Studies suggest that circulating antibodies in blood following vaccination trigger reactivation of HSV and VZV leading to idiopathic facial nerve palsy. ${ }^{5}$ Moreover, an immune reaction is necessary for efficacy of a vaccine and this response could be linked

\footnotetext{
(c) The Author(s). 2022 Open Access This article is distributed under the terms of the Creative Commons Attribution 4.0 International License (https://creativecommons. org/licenses/by-nc/4.0/), which permits unrestricted use, distribution, and non-commercial reproduction in any medium, provided you give appropriate credit to the original author(s) and the source, provide a link to the Creative Commons license, and indicate if changes were made. The Creative Commons Public Domain Dedication waiver (http://creativecommons.org/publicdomain/zero/1.0/) applies to the data made available in this article, unless otherwise stated.
} 
to facial nerve palsy development. BNT162b2 vaccine initiates an innate immune response and also interferon production. ${ }^{9}$ Some researchers are of the view that BP might be an adverse effect of interferon therapy. ${ }^{15}$

\section{Recommendations}

Based on the data from different studies, it is of utmost importance to perform a study on Indian population undergoing vaccination. Covaxin (BBV152) prepared by Bharat Biotech also makes use of inactivated viral particles, which might initiate an immune reaction leading to complications in some cases. In Indian population, the same might also be true for the most widely delivered Covishield vaccine. The reports also suggest that the third wave is going to hit India, wherein, children are at higher risk. Vaccination for below 18 years of age-group is also under discussion. Children with previous history of HSV and VZV infections should be specially taken care of and antiviral therapies should be planned for them before vaccination. Moreover, BP might be a symptom for asymptomatic COVID-19 patients and hence, general dentists should be aware of the squel of SARS-CoV-2 infections and treat any BP patient in the clinic after taking proper COVID-19 history. Due to variable rates of incidence across the countries, the connection between these two entities should be interpreted cautiously as it might influence the vaccination rate and increase the vaccine hesitancy. With aforementioned discussion in mind, the relevant patient history becomes an important parameter that can provide essential clues for the cause and effect relationship between these two entities.

\section{OrCID}

Sachin C Sarode ๑ https://orcid.org/0000-0003-1856-0957

\section{References}

1. Katyal N, Narula N, Acharya $S$, et al. Neuromuscular complications with SARS-COV-2 infection: a review. Front Neurol 2020;11:1052. DOI: 10.3389/fneur.2020.01052. PMID:33041989, PMCID:PMC7527465.

2. Carod-Artal FJ. Neurological complications of coronavirus and COVID-19. Rev Neurol (English, Spanish) 2020;70(9):311-322. DOI: 10.33588/rn.7009.2020179. PMID: 32329044.

3. Lima MA, Silva MTT, Soares $C N$, et al. Peripheral facial nerve palsy associated with COVID-19. J Neurovirol 2020;26(6):941-944. DOI: 10.1007/s13365-020-00912-6 (Epub: 2-10-20). PMID: 33006717, PMCID: PMC7531061.
4. Figueiredo R, Falcão V, Pinto MJ, et al. Peripheral facial paralysis as presenting symptom of COVID-19 in a pregnant woman. BMJ Case Rep 2020;13(8):e237146. DOI: 10.1136/bcr-2020-237146. PMID: 32784234, PMCID: PMC7418655.

5. Zhang W, Xu L, Luo T, et al. The etiology of Bell's palsy: a review. J Neurol 2020;267(7):1896-1905. DOI: 10.1007/s00415-019-092824 (Epub: 28-03-19). PMID: 30923934, PMCID: PMC7320932.

6. Le Balc'h P, Pinceaux K, Pronier C, et al. Herpes simplex virus and cytomegalovirus reactivations among severe COVID-19 patients. Crit Care 2020;24(1):530. DOI: 10.1186/s13054-020-03252-3. PMID: 32859241, PMCID: PMC7453668.

7. $\mathrm{Wu} Y, \mathrm{Xu} X, \mathrm{Chen} Z$, et al. Nervous system involvement after infection with COVID-19 and other coronaviruses. Brain Behav Immun 2020;87:18-22. DOI: 10.1016/j.bbi.2020.03.031 (Epub: Mar 30-03-20). PMID: 32240762, PMCID: PMC7146689.

8. Volk GF, Kuttenreich AM, Geitner M, et al. Eine akute Fazialisparese als mögliche Impfkomplikation bei einer Impfung gegen SARS-CoV-2 [Acute facial paresis as a possible complication of vaccination against SARS-CoV-2]. Laryngorhinootologie (German) 2021;100(7):526-528. DOI: 10.1055/a-1501-0470 (Epub: 11-05-21). PMID: 33975372.

9. Shemer A, Pras E, Einan-Lifshitz A, et al. Association of COVID-19 vaccination and facial nerve palsy: a case-control study. JAMA Otolaryngol Head Neck Surg 2021 (August 1);147(8):739-743. DOI: 10.1001/jamaoto.2021.1259. PMID: 34165512, PMCID: PMC8227442.

10. Polack FP, Thomas SJ, Kitchin N, et al. C4591001 clinical trial group. Safety and efficacy of the BNT162b2 mRNA COVID-19 vaccine. N Engl J Med 2020;383(27):2603-2615. DOI: 10.1056/NEJMoa2034577

11. Shimabukuro T. COVID-19 Vaccine Safety Update, Advisory Committee on Immunization Practices (ACIP) Meeting; January 27, 2021. Accessed January 30, 2021. https://www.cdc.gov/vaccines/acip/ meetings/downloads/slides-2021-01/06-COVID-Shimabukuro.pdf.

12. Wan EYF, Chui CSL, Lai FTT, et al. Bell's palsy following vaccination with mRNA (BNT162b2) and inactivated (CoronaVac) SARS-CoV-2 vaccines: a case series and nested case-control study. Lancet Infect Dis 2021. DOI: 10.1016/S1473-3099(21)00451-5 (Epub ahead of print). PMID: 34411532, PMCID: PMC8367195.

13. Martin Gl, Weintraub MI. Brachial neuritis and seventh nerve palsy. A rare hazard of DPT vaccination. Clin Pediatr 1973;12:506-507. DOI: $10.1177 / 000992287301200912$

14. Zhou W, Pool V, DeStefano F, et al. VAERS Working Group. A potential signal of Bell's palsy after parenteral inactivated influenza vaccines: reports to the Vaccine Adverse Event Reporting System (VAERS) - United States, 1991-2001. Pharmacoepidemiol Drug Saf 2004;13(8):505-510. DOI: 10.1002/pds.998

15. Hwang I, Calvit TB, Cash BD, et al. Bell's palsy: a rare complication of interferon therapy for hepatitis C. Dig Dis Sci 2004;49(4):619-620. DOI: 10.1023/b:ddas.0000026389.56819.0c. PMID: 15185866. 